\title{
Sprain or fracture? An analysis of 2000 ankle injuries
}

\author{
P. SUJITKUMAR, J. M. HADFIELD* AND D. W. YATES*
}

Accident and Emergency Department, Hope Hospital, Salford, England, and

*MRC Trauma Unit, Stopford Building, Oxford Road, Manchester, England

\section{SUMMARY}

A retrospective survey of over 2000 patients with inversion injuries of the ankle joint was undertaken to examine the validy of criteria commonly used in an accident and emergency department to assess severity.

Swelling alone is an unreliable indicator of the severity of the injury. Patients with severe pain and inability to weight bear show a high incidence of fractures and must be $\mathrm{X}$-rayed. Conversely, a combination of minimal pain and swelling, and ability to bear weight are indicative of a soft-tissue injury. Young people sustain most inversion injuries and have a lower incidence of significant fractures of the lateral malleolus.

Analysis of presenting features did not reveal any reliable indicants which could be used to reduce the number of radiographs requested, without substantially increasing the risk of missing patients with significant fractures. However, it has been possible to formulate guidelines for the more rational and consistent use of $\mathrm{X}$-rays in the initial assessment of patients with ankle sprains.

\section{INTRODUCTION}

Inversion sprains of the ankle joint are very common. In Salford, we treat over 2000 such injuries each year (about $4 \%$ of the total of new attenders). Radiographs of these injuries amount to $3 \%$ of the entire number performed throughout the hospital.

Many authors suggest that far too many $\mathrm{X}$-rays are requested but there is no agreement as to which patients should be excluded (DeLacey \& Bradbrooke 1979; Vargish et al., 1983). Similarly, there is no consensus as to the best form of management of partial tears of the lateral ligament in the accident and emergency department.

The objectives of the present study were to identify clinical features which correlated strongly with the presence of a significant fracture of the lateral malleolus and to 
establish guidelines concerning radiology for junior doctors in an accident and $\stackrel{\vec{\oplus}}{Q}$ emergency department.

A significant fracture was defined as one that involved the whole of the malleolus or the lower third of the fibula, with or without displacement. Minor flake fractures involving the tip of the lateral malleolus and dorsum of the tarsus, as well as the tip of $\stackrel{\vec{p}}{\vec{p}}$ the styloid process of the fifth metatarsal were studied as a separate group.

\section{SUBJECTS AND METHODS}

A retrospective study of presentation, assessment and some aspects of treatment was carried out on 2140 consecutive patients attending the Salford Accident and Emergency service with an ankle injury in 1982. The following categories of patients were excluded from this study:

(1) patients under 12 years;

(2) 'eversion' or deltoid ligament sprains;

(3) previously abnormal or unstable ankle joints;

(4) patients presenting with an obvious fracture which was apparent before an X-ray was taken.

After these criteria had been applied, 1600 patients were entered onto the study. $\overrightarrow{0}$ Information about each patient was assigned to the following three categories from the $\stackrel{\infty}{\circ}$ findings at the initial and subsequent clinical examinations.

History: Age, sex, place of incident, source of referral, delay in presentation, mod of arrival.

Initial examination: Degree of pain, degree of swelling, ability to bear weight, $\mathrm{X}$-ray. Treatment: Analgesia, physiotherapy.

Ten per cent of patients on the trial were randomly selected and sent a questionnaire to assess their opinion of the treatment received.

The results were analysed by computer using the Statistical Package for the Social Sciences (SPSS). A Chi-squared overall probabilities test for non-parametric data was used to test for significance.

\section{RESULTS}

From the original 2140 patients, $173(8 \%)$ were excluded because of a clinically obvious fracture. Another 367 patients had injuries to the medial side of the ankle, previously $\stackrel{\circ}{\circ}$ abnormal joints or were under 12 years old. Of the final 1600 cases studied, another $89 \mathrm{~N}$ $(5 \cdot 6 \%)$ had a significant fracture and $73(4 \cdot 6 \%)$ had an avulsion fracture. The remaining $1438(89 \cdot 8 \%)$ had soft-tissue injuries of varying severity.

\section{History}

The peak incidence of ankle injuries was seen between the ages of 17-35 years and the 
majority of attenders were under 35 years of age (Table 1). Injury to the 17-35 age group correlated highly $\left(\mathrm{X}^{2} P<0.005\right)$ with participation in sport.

Table 1 Distribution of ankle injuries with age.

\begin{tabular}{lllllllll}
\hline Age range (years) & $12-16$ & $17-25$ & $26-35$ & $36-45$ & $46-55$ & $56-65$ & $66-75$ & $75+$ \\
\hline $\begin{array}{l}\text { No. of patients } \\
\begin{array}{l}\text { Percentage of } \\
\text { significant fractures }\end{array}\end{array}$ & 278 & 491 & 321 & 183 & 140 & 109 & 55 & 16 \\
\hline
\end{tabular}

There was a greater preponderance of males with sprained ankles than females but no statistical differences between the two sexes with regard to the frequency of a fracture. The proportion of significant fractures increased with the age of patients of both sexes above 45 years.

Details of the places of injury are given in Fig. 1.

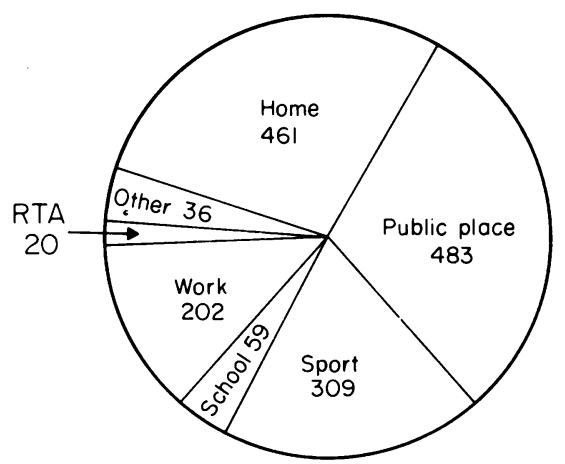

Fig. 1 Place of incident.

Eighty-five per cent of all patients attending were self referrals. Seventeen per cent of all patients with a significant facture were brought to hospital by ambulance in comparison with only $4 \%$ who arrived by ambulance with no significant bony injury.

The majority (75\%) of patients with an ankle injury presented within the first 24 hours and there was no evidence to suggest that patients with a fracture (whether or not significant) presented any earlier than patients with a sprain.

One third of the patients with a significant fracture arrived in a non weight-bearing condition. In comparison only $11 \%$ of those with ligamentous injuries were unable to bear weight.

\section{Initial examination}

The recorded presenting symptoms of patients from each of the three groups were compared by cross-tabulation. There was a high correlation $\left(X^{2} P<0.005\right)$ between the degree of pain and the presence of a significant fracture. The significant fracture group had a higher incidence of inability to bear weight. 
There was correlation between swelling and diagnosis $\left(X^{2} P<0.05\right)$, but a much higher correlation was apparent between degree of swelling and delay in presentation $\left(\mathrm{X}^{2} P<0.005\right)$. Fifteen per cent $(245)$ of patients presented with a combination of minimal pain and minimal swelling, and none of this group had sustained a significant fracture.

Table 2 Influence of presenting symptoms on diagnosis

\begin{tabular}{|c|c|c|c|}
\hline Clinical finding & $\begin{array}{c}\text { Percentage } \\
\text { of patients } \\
\text { with a significant } \\
\text { fracture }(n=89)\end{array}$ & $\begin{array}{c}\text { Percentage } \\
\text { of patients with } \\
\text { avulsion fracture } \\
(n=73)\end{array}$ & $\begin{array}{c}\text { Percentage } \\
\text { of patients } \\
\text { with sprain } \\
(n=1472)\end{array}$ \\
\hline Delay in presentation: $0-24 \mathrm{~h}$ & 73 & 70 & 70 \\
\hline $24-72 \mathrm{~h}$ & 7 & 15 & 9 \\
\hline $72+h$ & 9 & 4 & 11 \\
\hline unknown & 11 & 11 & 10 \\
\hline Little pain and swelling & 0 & 3 & 16 \\
\hline Moderate pain and swelling & 55 & 59 & 48 \\
\hline Severe pain and swelling & 6 & 4 & 2 \\
\hline Limping & 65 & 71 & 87 \\
\hline Non weight-bearing & 31 & 27 & 11 \\
\hline
\end{tabular}

Sixty-three per cent of patients were X-rayed at the first visit and $0.8 \%$ (13) hâ stress views taken. Five of these 13 patients were found to have unstable joints and wegge referred to the orthopaedic department. Nine per cent of all films taken on the fir attendance showed the presence of a significant fracture. A further seven significant fractures were missed because radiographs were not taken at the first visit. These $\stackrel{\triangleright}{\circledR}$ fractures were subsequently diagnosed, after radiography by a senior doctor in a review $\overrightarrow{\vec{O}}$ clinic.

\section{Treatment}

Analgesia was prescribed to $12.4 \%$ of all patients and $22.5 \%$ of those with significant fractures.

Nineteen per cent of all soft-tissue injuries were given physiotherapy. This figure was the same for patients with avulsion fractures whose ankles were not immobilised.

Table 3 Random sample questionnaire*

\begin{tabular}{lc}
\hline Opions on treatment & Percentage \\
\hline Satisfied & 85 \\
Not given analgesia & 7 \\
Unhappy with support & 5 \\
Not given crutches & 2 \\
Too long to wait for treatment & 1 \\
\hline${ }^{*} n=109$ completed replies. &
\end{tabular}


The random sample questionnaire concerning attitudes to treatment achieved a $68 \%$ response rate. The results are given in Table 3.

\section{DISCUSSION}

Brooks et al., (1981) suggested that clinical examination alone is accurate enough to diagnose fractures. However, their results do not entirely support this statement, perhaps because only 241 patients were studied. They did not show any difference in the degree of pain or swelling in their sprain and fracture groups. Vargish et al., (1983) studied 24 independent variables and combinations of variables in 150 patients, and concluded that the only useful indicators of severity were the patient's ability to bear weight on the injured side and the presence or absence of tenderness over the lateral aspect of the ankle.

Our survey is based on the case notes of a very large sample of patients. The results suggest that patients with minimal pain and swelling who are able to weight bear need not be X-rayed. Patients in the younger age group (below 50 years) with a moderate degree of pain should be carefully clinically assessed before radiology is requested. Older patients with moderate or severe pain should be X-rayed.

We could not identify any combination of clinical symptoms which, when applied to every patient, would always accurately predict the presence of a fracture. The inexperienced may be influenced by the degree of swelling when requesting radiographs and deciding treatment. However, the degree of swelling is directly related to the delay in presentation, and to the patients' behaviour and mobility after the accident as well as to the severity of injury. Swelling cannot be used simply as an indicator of severity or of the need to take an $\mathrm{X}$-ray. In our study seven significant fractures were missed $(0 \cdot 4 \%$ of the total 1600 patients). Six of these patients had moderate or severe pain. Only one had slight pain and moderate swelling.

It has been shown (DeLacey et al., 1979; Warren \& Fergusson, 1984) that accident and emergency doctors request large numbers of $\mathrm{X}$-rays as a 'safety net'. A more appropriate use of $\mathrm{X}$-rays could be achieved by adopting the guidelines set out in Table 4. These are, however, unlikely to reduce the total number of films taken. An internal audit should ensure the return of any patients whose fractures are missed at the first visit.

Table 4 Guidelines for radiography of ankle injuries in the accident and emergency department.

1. Older patients with moderate or severe pain should always be $\mathrm{X}$-rayed.

2. Patients below 50 years with a moderate degree of pain should be carefully assessed clinically before radiology is requested.

3. Patients with minimal pain and minimal swelling who are able to bear weight need not be $\mathrm{X}$-rayed.

4. Swelling is not a reliable guide to the presence of a significance fracture. 
This survey had not compared different forms of treatment, but the responses to our ${ }_{\mathbb{\Phi}}^{3}$ questionnaire suggest that some of our patients did not receive adequate analgesia or $\overline{0}$ support either locally or in the form of crutches.

Whatever specific treatment is chosen, the financial cost of ligamentous injuries and $\stackrel{\odot}{\circ}$ the time to full recovery are more likely to be reduced by instituting early therapy rather $\overrightarrow{\vec{N}}$ than by restricting the number of radiographs. However the guidelines listed in Table $4 \overline{0}$ should increase the positive yield from this investigation and thereby reduce unnecessary morbidity.

\section{REFERENCES}

Brooks S. C., Potter B. T. \& Rainey J. B. (1981) Inversion injuries of the ankle: clinical assessment and radiographic review. British Medical fournal 282, 607-8.

DeLacey G., Bradbrooke S. (1979) Rationalising requests for X-ray examination of acute ankle injuries. i British Medical fournal 280, 1597-8.

DeLacey G., Barker A., Wignall B., Reidy J. \& Harper J. (1979) Reasons for requesting radiographs in an accident department. British Medical fournal 280, 1595-7.

Vargish T., Clarke W. R., Young R. A. \& Jensen, A. (1983) The ankle injury-indications for the selective use of X-rays. Injury 14, 507-12.

Warren R. A. \& Fergusson D. G. (1984) Why do accident and emergency doctors request X-rays? Archives of $\overline{(D}$ Emergency Medicine 1, 143-50.

Received 6 August 1985; accepted 15 November 1985 